\title{
Studied on the extraction, response surface analysis and antioxidant activity of flavonoids in the Momordia cochinchinensis seeds
}

\author{
Junyu Jiang, Aiping Fei, Yong Wang, Zhigang Fang, Yingxue Teng, Xiaoliang Hao* \\ University of Science and Technology Liaoning, Anshan China, 114000
}

\begin{abstract}
This text was mainly studied the extraction flavonoids technology from Momordia cochinchinensis seeds. The optimum extraction condition was as follows: when the ratio of liquid to solid was 20:1, the ethanol concentration was $90 \%$ and the extraction time was $2 \mathrm{~h}$. Under this condition, the actual average yield of flavonoids could reach $0.363 \%$.
\end{abstract}

\section{INTRODUCTION}

More and more attentions have been paid to the natural products, especially the products derived from medicinal plants. Some plant natural products have many advantages, which could be used in many fields, such as drug discovery, anticancer, immunity, etc. Many diseases of human beings are closely related to the free radicals in the human body ${ }^{[1]}$. There are some certain relationships between free radicals and antioxidation. Potential sources of antioxidant compounds have been searched in several types of plant materials such as vegetables, fruits, leaves, oilseeds, and many other sources ${ }^{[2]}$. Compared with synthetic antioxidants, natural plant antioxidants have many advantages, especially safety ${ }^{[3]}$.

Antioxidants are compounds that inhibit or delay the oxidation of other molecules by initiation or propagation of oxidizing chain reactions ${ }^{[4]}$. Natural products contain many functional compounds, and the exertion of these natural products depends to a large extent on these functional compounds ${ }^{[5]}$. Flavonoids are parts of these functional compounds and play a preventive role in the development of cancer and heart disease ${ }^{[6-7]}$.

Momordia cochinchinensis is a kind of medicine plant whose seeds, roots and leaves have been used as food. Momordia cochinchinensis contains many functional compounds, such as the flavonoids compounds ${ }^{[8]}$.

Ultrasound-assisted extraction (USAE) is an important method to obtain high valuable compounds and could contribute to the increase in the value of some food ${ }^{[9]}$. In our study, USAE method was used to extract the Momordia cochinchinensis seed. The procedure condition was optimized by using response surface. The infrared spectrum and high performance liquid chromatography (HPLC) were also used to confirm the existence of flavonoids.

\footnotetext{
a Corresponding author: Haoxiaoliang1980@163.com
}

\section{MATERIALS AND METHODS}

\subsection{Materials}

Momordia cochinchinensis seeds were purchased from the local supermarket. Anhydrous ethanol, sodium nitrite, aluminum sulfate, sodium hydroxide were obtained from Beijing North Chemical Fine Chemicals Co., Ltd. Rutin, quercetin, EDTA (disodium ethylenediamine tetraacetic acid), saffron red, o-phenol, disodium hydrogen phosphate, sodium dihydrogen phosphate, and sodium dihydrogen phosphate were purchased from National drug group chemical reagents Co., Ltd. All the reagents were analytically pure.

\subsection{Instruments}

Dfy-400 high-speed universal mill (Wenling Linda machinery manufacturing co., LTD); 00000792-1 electronic balance (Zhuji chaoze equalizer equipment co., LTD); Kq-250b, ultrasonic cleaner (Kunshan ultrasonic instrument co., LTD); ReactlR 15 infrared analyzer (German mettler company); 1100 chromatographic analyzer (Agilent company).

\subsection{Experimental}

\subsubsection{Extraction procedure of flavonoids}

Momordia cochinchinensis seeds were ground to powder and weighed to $1.00 \mathrm{~g}$, the powder and a certain volume ethanol solution were added into the triangular flask. The flask was placed into the ultrasonic cleaner, temperature was set as $50{ }^{\circ} \mathrm{C}$, power was set as $400 \mathrm{~W}$. After extraction, the solution was filtered by filter paper. 


\subsubsection{Standard curve of rutin}

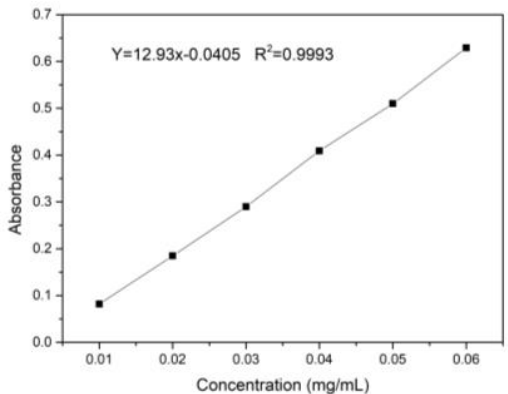

Figure 1. Standard curve of rutin.

Momordia cochinchinensis seeds were dried at $105{ }^{\circ} \mathrm{C}$. After the powder was smashed and weighed, $95 \%$ ethanol was added, the final volume of the solution was $10 \mathrm{ml}$.

\subsubsection{Calculation of flavonoids extraction rate}

The flavonoids extraction rate $\mathrm{C} \%$ was calculated according to the formula (1).

$$
C(\%)=\frac{V \times X}{100 \times A \times W} \times 100 \%
$$

$\mathrm{X}$ : flavonoids extraction rate $(\mathrm{mg} / \mathrm{ml})$

$\mathrm{V}$ : extraction volume $(\mathrm{ml})$

A: sample volume $(\mathrm{ml})$

W: sample weight $(\mathrm{g})$

\subsubsection{Antioxidant analysis}

(1) Scavenging of superoxide anion free radical

In this experiment, the phthalic three phenol self oxidation method was used. The absorbance value was determined at $325 \mathrm{~nm}$. The self oxidation rate of ophenylene three phenol was calculated by using the Tris$\mathrm{HCl}$ buffer solution $(\mathrm{pH}=8.2)$ as blank. Inhibition rate was calculated according to the formula (2).

$$
\text { Inhibition } \operatorname{rate}(\%)=\left(A_{0}-A_{1}\right) / A_{0} \times 100
$$

$\mathrm{A}_{0}$ : absorbance of blank sample

$\mathrm{A}_{1}$ : absorbance of flavonoids solution

(2) Scavenging effect of hydroxyl radical

The first test tube was added by $0.2 \mathrm{~mol} / 1$ phosphoric acid buffer $(\mathrm{pH}=7.4)$, and $0.2 \mathrm{ml} 520 \mathrm{mg} / \mathrm{l}$ reddish red solution was added; the other 8 test tubes were added by $1.0 \mathrm{ml} 0.2 \mathrm{~mol} / \mathrm{l}$ phosphate buffer $(\mathrm{pH}=7.4), 0.2 \mathrm{ml} 520$ $\mathrm{mg} / \mathrm{l}$ reddish red solution and $1.0 \mathrm{ml}$ EDTANa ${ }^{2}-\mathrm{Fe}^{2+}$. Then the distilled water $(7,6,5,4,3,3,3,0 \mathrm{ml})$ was added, respectively. Finally $0.8 \mathrm{ml} 6 \% \mathrm{H}_{2} \mathrm{O}_{2}$ solution was added, with heated $30 \mathrm{~min}$ in water bath pot, the absorbance value at $520 \mathrm{~nm}$ was measured. Scavenging rate (S) was calculated according to the formula (3).

$S(\%)=\left(A_{\text {Sample }}-A_{\text {Blank }}\right) /\left(A_{\text {Contrast }}-A_{\text {Blank }}\right) \times 100 \%$

\section{RESULTS AND DISSCUSSION}

\subsection{Single factor experiment}

\subsubsection{Effect of ratio of liquid to solid on flavonoids extraction}

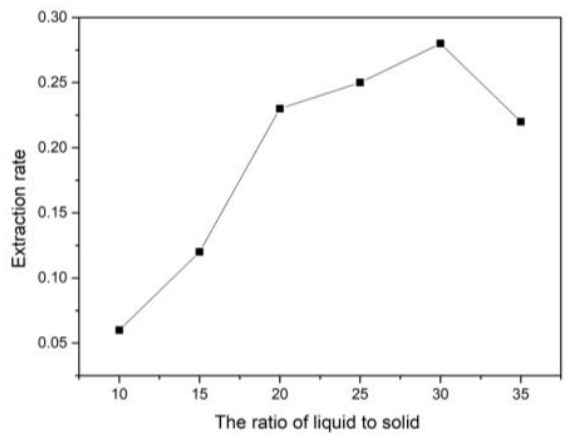

Figure 2. Effect of ratio of liquid to solid on flavonoids extraction.

As shown in Figure 2, the increase in the amount of solvent was conducive to the precipitation of flavonoids. However, under a certain amount, the flavonoids extraction rate was increased slowly, when the ratio reached 30:1, the extraction rate began to decline.

\subsubsection{Effect of ethanol concentration on flavonoids extraction}

As shown in Figure 3, at first, the flavonoids extraction rate was increased and then decreased with the increase of ethanol concentration. The reason might be that with the increase of concentration, the solvent polarity was decreased and the dissolution rate of flavonoids was decreased.

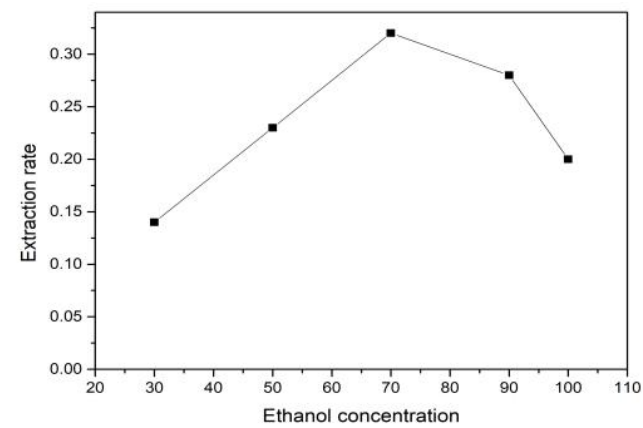

Figure 3. Effect of ethanol concentration on the flavonoids extraction rate.

\subsubsection{Effect of ultrasonic time on the extraction} effect of flavonoids

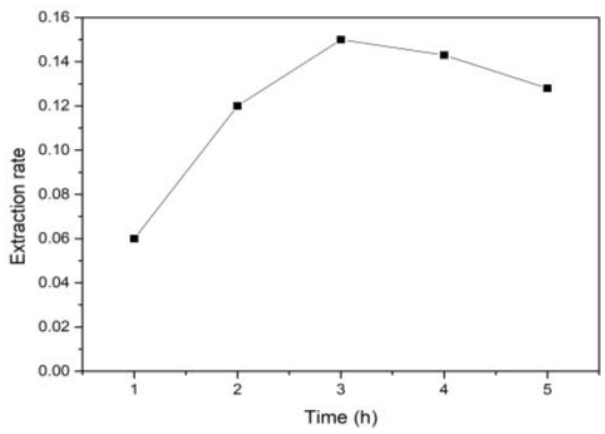

Figure 4. Effect of ultrasonic time on flavonoids extraction. 
$50{ }^{\circ} \mathrm{C}$ was set as the extraction temperature, ultrasonic power was set as $400 \mathrm{~W}, 70 \%$ was set as the ethanol concentration. Figure 4 showed that before 3 hours with the extension of ultrasonic time, the flavonoids extraction rate was increased, and after 3 hours, the extraction rate showed a downward trend, the reason might be that with the incerase of the extraction time, the solvent was evaporated.

\subsection{Experimental results of response surface}

The Box Behnken model by software Design Expert 8.0.6 was used to design the response surface experiment. The design parameter contained the ratio of liquid to solid, ultrasonic time and ethanol concentration ${ }^{[10]}$.

Table 1. Response surface factor and level table.

\begin{tabular}{cccc}
\hline Code & $\begin{array}{c}\text { Ratio of liquid to } \\
\text { solid (A) }\end{array}$ & $\begin{array}{c}\text { Ethanol } \\
\text { concentration (B) }\end{array}$ & Time (C) \\
\hline-1 & $10: 1$ & 50 & 1 \\
0 & $20: 1$ & 70 & 2 \\
1 & $30: 1$ & 90 & 3 \\
\hline
\end{tabular}

Table 2. Design and the results of the response surface.

\begin{tabular}{|c|c|c|c|c|}
\hline No & $\begin{array}{r}\text { Ratio of } \\
\text { liquid to } \\
\text { solid (A) }\end{array}$ & $\begin{array}{c}\text { Ethanol } \\
\text { concentration } \\
\text { (B) }\end{array}$ & $\begin{array}{l}\text { Time } \\
\text { (C) }\end{array}$ & $\begin{array}{c}\text { Extraction } \\
\text { rate }\end{array}$ \\
\hline 1 & -1 & -1 & 0 & 0.06 \\
\hline 2 & 1 & -1 & 0 & 0.14 \\
\hline 3 & -1 & 1 & 0 & 0.19 \\
\hline 4 & 1 & 1 & 0 & 0.31 \\
\hline 5 & -1 & 0 & -1 & 0.07 \\
\hline 6 & 1 & 0 & -1 & 0.21 \\
\hline 7 & -1 & 0 & 1 & 0.08 \\
\hline 8 & 1 & 0 & 1 & 0.24 \\
\hline 9 & 0 & -1 & -1 & 0.10 \\
\hline 10 & 0 & 1 & -1 & 0.29 \\
\hline 11 & 0 & -1 & 1 & 0.10 \\
\hline 12 & 0 & 1 & 1 & 0.27 \\
\hline 13 & 0 & 0 & 0 & 0.12 \\
\hline 14 & 0 & 0 & 0 & 0.12 \\
\hline 15 & 0 & 0 & 0 & 0.13 \\
\hline 16 & 0 & 0 & 0 & 0.14 \\
\hline 17 & 0 & 0 & 0 & 0.13 \\
\hline
\end{tabular}

The multiple regression equation model was obtained: $\mathrm{Y}=0.13+0.063 \mathrm{~A}+0.083 \mathrm{~B}+2.500 \times 10^{-3} \mathrm{C}+1.000 \times 10^{-2} \mathrm{AB}$ $+5.000 \times 10^{-3} \mathrm{AC}-5.000 \times 10^{-3} \mathrm{BC}+3.500 \times 10^{-3} \mathrm{~A}^{2}+0.043 \mathrm{~B}^{2}$ $+0.018 \mathrm{C}^{2}$ 。

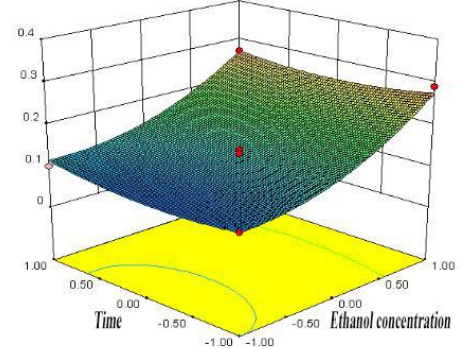

Figure 5. Interaction between ultrasonic time and ethanol concentration on flavonoids extraction rate.

According to the results of response surface, the optimized process condition was that: when ultrasonic time was $1.95 \mathrm{~h}$, the ratio of liquid to solid was 20:1 $(\mathrm{ml} / \mathrm{g})$, and the ethanol concentration was $83.26 \%$, the predicted extraction rate of flavonoids was $0.363 \%$. Considering the convenience of the actual operation, the condition in the optimized process was modified to: the ultrasonic time $2 \mathrm{~h}$, the ratio of liquid to solid 20:1 (ml/g) and the ethanol concentration $90 \%$. Three parallel repeated validation experiments were conducted, and the average flavonoids extraction rate under the modified conditions was $0.378 \%$. The experimental value was only $0.015 \%$ different from the predicted value of the model equation, indicating that the optimized extraction condition by response surface method was accurate.

Table 3. Variance analysis of the response surface results.

\begin{tabular}{ccccc}
\hline $\begin{array}{c}\text { Source of } \\
\text { variance }\end{array}$ & $\begin{array}{c}\text { Sum of } \\
\text { squares }\end{array}$ & $\begin{array}{c}\text { mean } \\
\text { square }\end{array}$ & $\begin{array}{c}\mathrm{F} \\
\text { value }\end{array}$ & P value \\
\hline Model & 0.095 & 0.011 & 30.84 & $\begin{array}{c}<0.000 \\
1\end{array}$ \\
A & 0.031 & 0.031 & 90.02 & $\begin{array}{c}<0.000 \\
1\end{array}$ \\
C & $5.000 \times 10^{-5}$ & $\begin{array}{c}5.000 \times 10^{-} \\
3\end{array}$ & 0.14 & 0.7156 \\
AB & $4.000 \times 10^{-4}$ & $\begin{array}{c}4.000 \times 10^{-} \\
4\end{array}$ & 1.15 & 0.3187 \\
AC & $1.000 \times 10^{-4}$ & $\begin{array}{c}1.000 \times 10^{-} \\
4\end{array}$ & 0.29 & 0.6081 \\
BC & $1.000 \times 10^{-4}$ & $\begin{array}{c}1.000 \times 10^{-} \\
4\end{array}$ & 0.29 & 0.6081 \\
A $^{2}$ & $5.158 \times 10^{-5}$ & $\begin{array}{c}5.158 \times 10^{-} \\
5\end{array}$ & 0.15 & 0.7113 \\
$B^{2}$ & $7.967 \times 10^{-3}$ & $\begin{array}{c}7.967 \times 10^{-} \\
3\end{array}$ & 22.95 & 0.0020 \\
$C^{2}$ & $1.441 \times 10^{-3}$ & $\begin{array}{c}1.441 \times 10^{-} \\
3\end{array}$ & 4.15 & 0.0310 \\
Residual & $2.430 \times 10^{-3}$ & $\begin{array}{c}3.471 \times 10^{-} \\
4\end{array}$ & & \\
Unintended \\
term
\end{tabular}




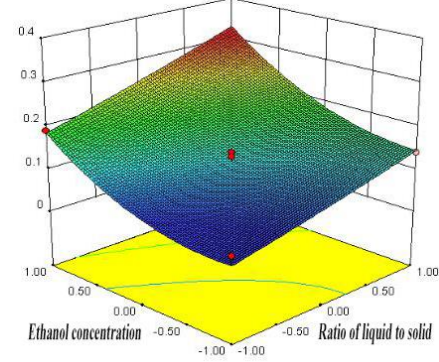

Figure 6. Interaction of ratio of liquid to solid and ethanol concentration on flavonoids extraction rate.

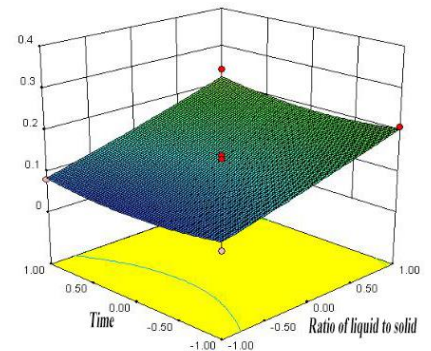

Figure 7. Interaction between ultrasonic time and ratio of liquid to solid on flavonoids extraction rate.

It could be seen in Figure 5, 6 and 7 that ethanol concentration had the greatest influence on the extraction rate, followed by ratio of liquid to solid and ultrasonic time.

\subsection{Infrared spectral characteristics and analysis}

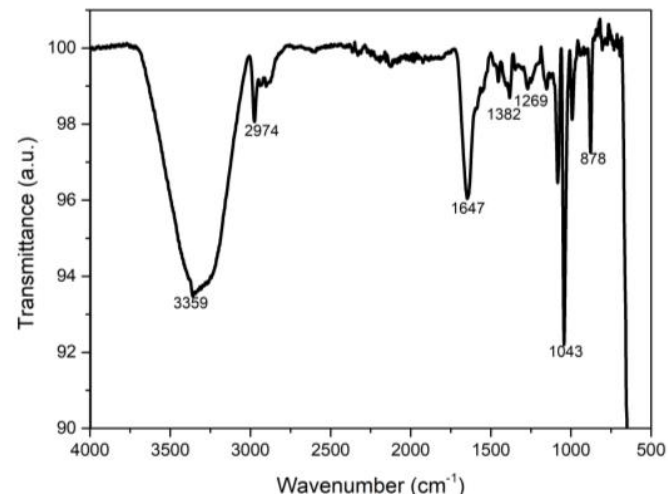

Figure 8. Spectrogram of flavonoids in the Momordica cochinchinensis.

It could be seen in Figure 8, there was a strong absorption peak at $3359 \mathrm{~cm}^{-1}$, indicating that there was a large amount of phenolic or hydroxyl groups. The $-\mathrm{CH}$ stretching vibration was found at $2974 \mathrm{~cm}^{-1}$. C $=\mathrm{C}$ double bond was found at $1647 \mathrm{~cm}^{-1}$.-CH3 was appeared at 1382 $\mathrm{cm}^{-1}$. The peak $1269 \mathrm{~cm}^{-1}$ was C-C skeleton vibration absorption peak. The absorption peak at $1043 \mathrm{~cm}^{-1}$ was the stretching vibration peak of C-O. The peak $878 \mathrm{~cm}^{-1}$ might be hexagon double oxygen ring.

\subsection{Analysis of HPLC results}

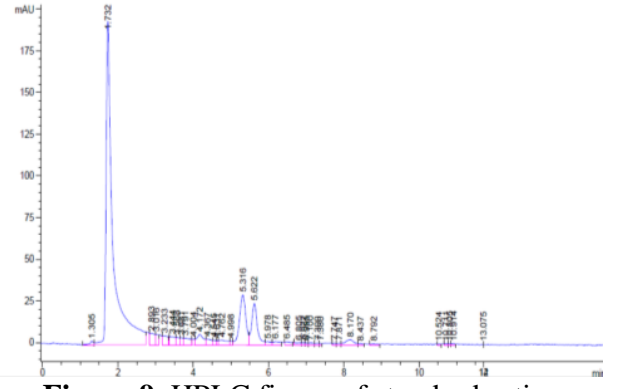

Figure 9. HPLC figure of standard rutin.

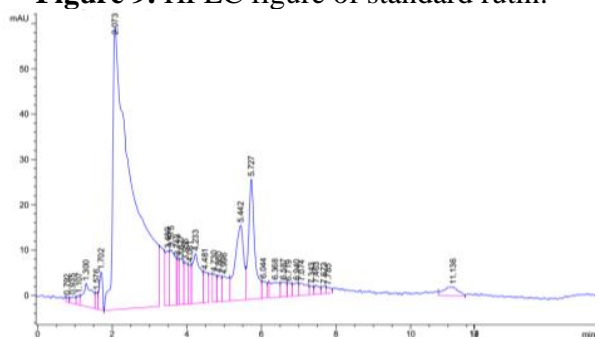

Figure 10. HPLC figure of standard quercetin.

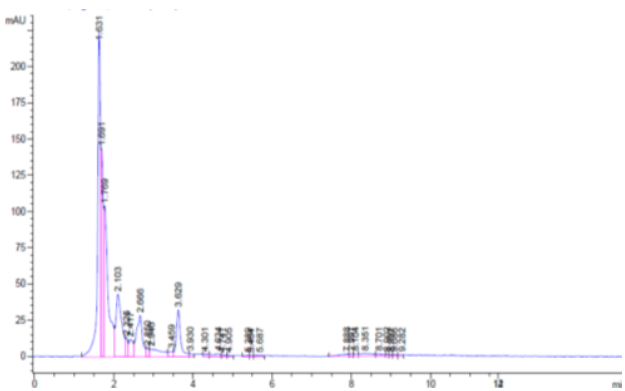

Figure 11. HPLC figure of the extraction solution.

As shown in the figures above, the peak of rutin was appeared at $1.732 \mathrm{~min}$, the peak of quercetin was appeared at $2.073 \mathrm{~min}$, the peak of the extraction solution was appeared at $1.631 \mathrm{~min}$, followed by $1.691 \mathrm{~min}, 1.769$ min, and $2.103 \mathrm{~min}$, which indicating that the compound might contain substances similar to rutin and quercetin.

\subsection{Antioxidant analysis}

\subsubsection{Scavenging of superoxide anion free radical}

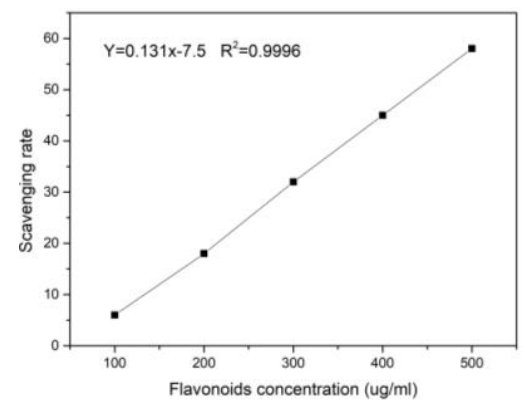

Figure 12. Scavenging ability of flavonoids in the kernel of chiton sinensis to superoxide anion free radicals.

As shown in Figure 12, the flavonoids solution had a good scavenging ability to superoxide anion free radicals, and the scavenging rate was increased with the increase of flavonoids concentration ${ }^{[11]}$.

\subsubsection{Scavenging hydroxyl radical}




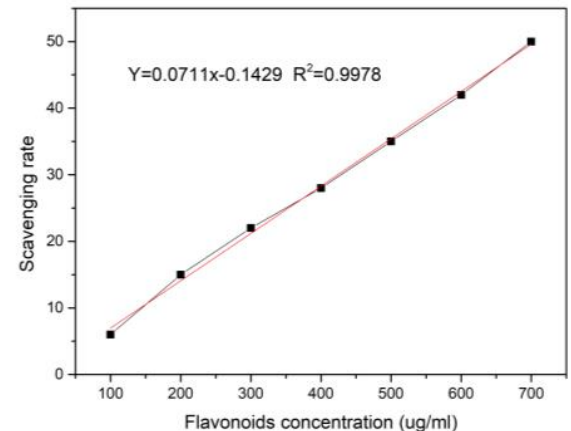

Figure 13. Ability of scavenging hydroxyl radical.

Figure 13 showed that flavonoids solution had the higher scavenging ability for hydroxyl radicals. Moreover, its antioxidant capacity was increased with the increase of flavonoids in the extraction solution. There was a good linear relation in the range of $0-700 \mathrm{ug} / \mathrm{ml}$.

\section{Conclusions}

According to the optimization of response surface, under the condition of $400 \mathrm{~W}$ ultrasonic power, the optimal extraction condition of Momordia cochinchinensis seeds flavonoids was: the ratio of liquid to solid was 20:1, the ethanol concentration was $90 \%$ and the extraction time was $2 \mathrm{~h}$. Under this condition, the actual average yield of flavonoids could reach $0.363 \%$, which was close to the predicted value of $0.378 \%$.

It is a good research direction to extract functional compounds from natural products and use them as natural antioxidants. The purpose of this study is to provide references for the extraction of natural products by studying the extraction conditions, we hope more and more natural functional compounds could be developed to new pharmaceutical preparations and benefited human health.

\section{Acknowledge}

This work was financially supported by Liaoning Natural Science Foundation Project (project number: 20170520093, 20170540466), Liaoning Provincial Education Office Service Local Project (project number: 2017FWDF05).

\section{References}

1. Adina Elena Segneanu, Daniel Damian, Iosif Hulka, Ioan Grozescu, Athanasios Salifoglou. A simple and rapid method for calixarene based selective extraction of bioactive molecules from natural products[J]. Amino Acids 48:849-858 (2016)

2. Ramarathnam, N.Ochi, H.; Takeuchi, M. Antioxidant defense system in vegetable extracts. In Natural Antioxidants: Chemistry, Health Effects, and Applications; Shahidi, F., Ed.; AOCS Press: Champaign, IL, 76-87 (1997)

3. Larson, R. A. The antioxidants of higher plants. Phytochemistry, 27, 969-978 (1988)
4. S. Velioglu, G. Mazza, L. Gao, and B. D. Oomah.Antioxidant Activity and Total Phenolics in Selected Fruits, Vegetables, and Grain Products[J]. Agric. Food Chem, 46, 4113-4117 (1998)

5. Marja P. Kähkönen, Anu I. Hopia, Heikki J. Vuorela, Jussi-Pekka Rauha, Kalevi Pihlaja,Tytti S. Kujala, and Marina Heinonen. Antioxidant Activity of Plant Extracts Containing Phenolic Compounds[J]. Agric. Food Chem, 47, 3954-3962 (1999)

6. Serafini, M.; Maiani, G.; Ferro-Luzzi, A. Alcoholfree red wine enhances plasma antioxidant capacity in humans[J]. Nutr, 128 (6), 1003-1007 (1998)

7. Carbonneau, M.-A.; Le'ger, C. L.; Descomps, B.; Michel, F.; Monnier, L. Improvement in the antioxidant status of plasma and low-density lipoprotein in subjects receiving a red wine phenolics mixture[J]. Am. Oil Chem. Soc,75, 235240 (1998)

8. Chen J, Chen SK. Spermatophyta. In: Wu ZY, editor. Flora Yunnanica. 1st ed. Beijing: Science Press; 329-30 (1995)

9. D. Esclapez, J. V. Garci'a-Pe'rez, A. Mulet, J. A $\mathrm{Ca}$ 'rcel.Ultrasound-Assisted Extraction of Natural Products[J]. Food Eng Rev, 3:108-120 (2011)

10. Sibel Tunali Akar, Fatih Sayin, Serpil Turkyilmaz, Tamer Akar. Multivariate optimization of the decolorization process by surface modified biomaterial: Box-Behnken design and mechanism analysis[J]. Environ Sci Pollut Res, 21:13055-13068 (2014)

11. Baudouin C, Pisella PJ, Ettaiche M, Goldschild M, Becquet F, Gastaud P, Droy-Lefaix MT.Effects of EGb761 and superoxide dismutase in an experimental model of retinopathy generated by intravitreal production of superoxide anion radical[J]. Graefes Arch Clin Exp Ophthalmol, 237 (1): 58-66 (1999) 